\title{
Comparison between UNS S32101 and UNS S32205 hydrogenated
}

\author{
Angela Maria Cordeiro de Oliveira ${ }^{1,3}$, Ramón Sigifredo Cortés Paredes ${ }^{1}$, Walmor Cardoso Godoi ${ }^{2}$ \\ and Sergio Luiz Henke ${ }^{1}$ \\ ${ }^{1}$ Federal University of Paraná, Polytechnic Center, Curitiba, Brazil \\ ${ }^{2}$ Federal Technological University of Paraná - Department of Physics, Brazil. \\ ${ }^{3}$ Faculty Estacio of Curitiba, Paraná, Brazil.
}

\begin{abstract}
This work presents a study on the duplex stainless steels UNS S32101 and UNS S32205 when subjected to cathodic hydrogenation, to ascertain their behavior under the action of hydrogen. It was evaluated for embrittlement and phase transformations induced by hydrogen, in order to check whether nickel and molybdenum contents would improve resistance to the harmful effects of hydrogen. With the aid of optical (MO) and scanning electron microscopy (SEM), both hydrogen embrittlement in both steels after hydrogenation and degassing was evidenced, as well as pitting corrosion on UNS S32101 duplex stainless steel. It appears that hydrogen can induce the transformation of the austenitic phase $(\gamma)$ into the martensitic phase $\left(\alpha^{\prime}\right)$ in the two duplex stainless steels analyzed and it is verified that hydrogen can lead to the formation of sigma phase at room temperature in duplex stainless steel UNS type S32101.
\end{abstract}

Keywords: Hydrogen embrittlement, Phase transformation, Pitting corrosion, Duplex stainless steel.

\section{Introduction}

Firstly, due to the increase in the price of nickel, studies on duplex stainless steels have intensified since the 1990s [1-3]. In this way, the growth of scientific interest in the field of materials promoted discussion about the microstructure and the combination of properties, such are usually obtained by increasing the levels of chromium, molybdenum and nitrogen when compared with austenitic stainless steels [4]. Thus justifying the price increase identified since 1990.

Following, it is highlighted that there is a considerable risk of catastrophic failures caused by hydrogen in the operations of extraction, production and refining of oil. Since, microstructural analyzes show that hydrogen induces phase transformations, that is, austenite becomes unstable giving rise to two martensitic phases, one called the $\varepsilon$ phase, and the other called the $\alpha$ 'phase [5-7]. As well as the formation of precipitates of type $\mathrm{Cr} 23 \mathrm{C} 6$ in ferritic grains during hydrogenation and high energy in the disappearance of these during degassing, sufficient for the formation of the sigma phase $(\sigma)$ in stainless steel UNS S32101 [8]. It is worth mentioning that hydrogen also induces the appearance of delayed fracture, as a consequence of the appearance of numerous surface cracks, which occur during degassing at room temperature. Mechanical tests reveal that: hydrogen drastically reduces the ductility of a material, causing it to break with a fragile characteristic when subjected to tensile tests; and it also reduces the fatigue life of the material $[9,10]$. Therefore, the appropriate choice of material to work in hydrogenated environments must be very careful, as it is extremely necessary to know the mechanical-metallurgical behavior in environments rich in hydrogen.

Thus, the objective of this study is to analyze hydrogen embrittlement, as well as the phase transformations induced by it in the duplex stainless steels UNS S32101 and UNS S32205, when subjected to cathodic hydrogenation.

\section{Experimental Procedure}

For broad understanding, UNS S2101 and UNS S2205 duplex stainless steels were machined until they acquired a smooth surface. Then, with a cutting disc, $1.0 \mathrm{~cm} 2$ samples were cut, then the samples were 
embedded, mechanically sanded in paper sandpaper (with $220 \mu \mathrm{m}$ and $1200 \mu \mathrm{m}$ grain sizes), polished with felt cloth and aluminum alumina. granulometry $0.30 \mu \mathrm{m}$, in the sequence neoprene cloth and $0.1 \mu \mathrm{m}$ colloidal silica, to guarantee (smooth) surfaces that can be analyzed through optical microscopy, electron microscopy and X-ray diffraction. After polishing, the samples of the duplex steels were subjected to cathodic hydrogenation for four hours at a temperature of $30^{\circ} \mathrm{C}$.

The solution was prepared as follows: dilution of $1 \mathrm{~g}$ of $\mathrm{As} 2 \mathrm{O} 3$ in $1 \mathrm{~L}$ of distilled water at $80^{\circ} \mathrm{C}$. The hydrogenation solution: consisted of diluting $100 \mathrm{ml}$ of the arsenic trioxide solution in a $0.5 \mathrm{~mol} \mathrm{~L}-1$ solution of $\mathrm{H} 2 \mathrm{SO} 4.27 \mathrm{ml}$ of $\mathrm{H} 2 \mathrm{SO} 4$ was applied in 1 liter of solution. In this solution, arsenic trioxide was applied to avoid loss of hydrogen to the atmosphere. A platinum anode and a current density of $1000 \mathrm{~A} / \mathrm{m} 2$ were used. Figure 1 presents a representative diagram of the hydrogenation process.

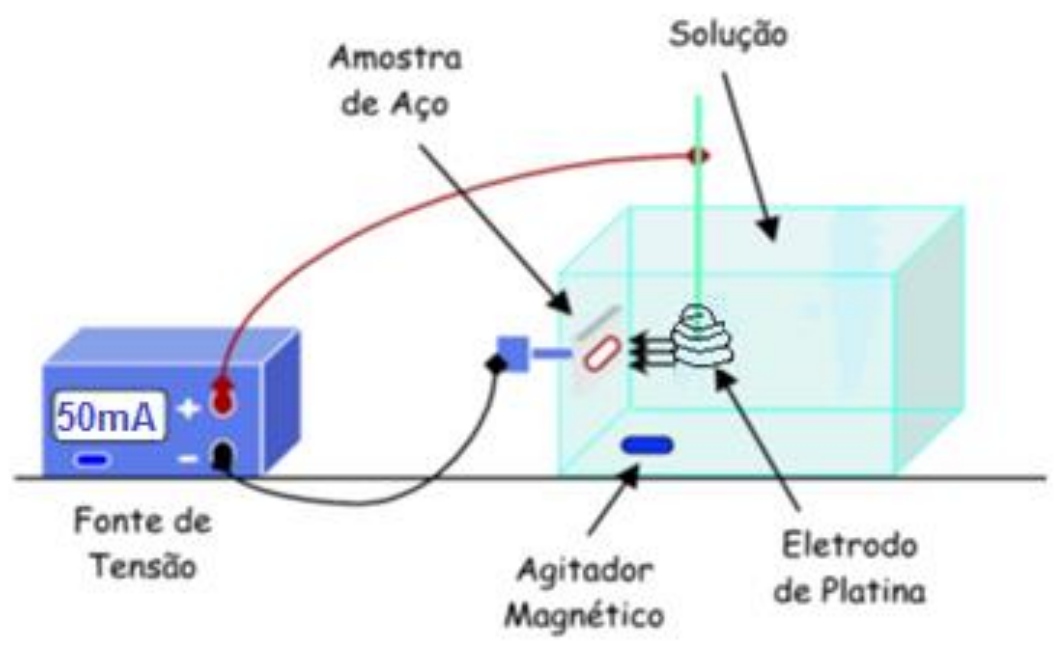

Figure 1: Schematic of the hydrogenation process. Source: the author.

The samples were kept at room temperature after the hydrogenation was interrupted to degass and subsequently observed for damage caused by hydrogen. The damage caused by optical microscopy and scanning electron microscopy was evaluated, as well as analyzed by X-ray diffraction.

\section{Results And Discussions}

In order to verify the microcracks, generated in the degassing process after cathodic hydrogenation, optical microscopy (OM) images were sought. Since this hydrogen embrittlement in this type of steel was expected, especially in austenitic grains, as, as already discussed in other studies, there is an intense surface cracking of austenitic stainless steel after hydrogenation [11-13, 16].

Therefore, in order to visualize the damages caused during the hydrogenation and degassing process, optical microscopy and scanning electron microscopy were used. Thus, it can be seen that in figures 2 and 3 are optical micrographs of duplex stainless steel of the UNS S32101 type. Figure 2 of this steel is only sanded, polished and attacked (Murakami) to reveal the ferritic $(\alpha)$ and austenitic $(\gamma)$ grains. Figure 3 is the UNS S32101 duplex stainless steel sanded, polished, hydrogenated for 4 hours and degassed for a week. 


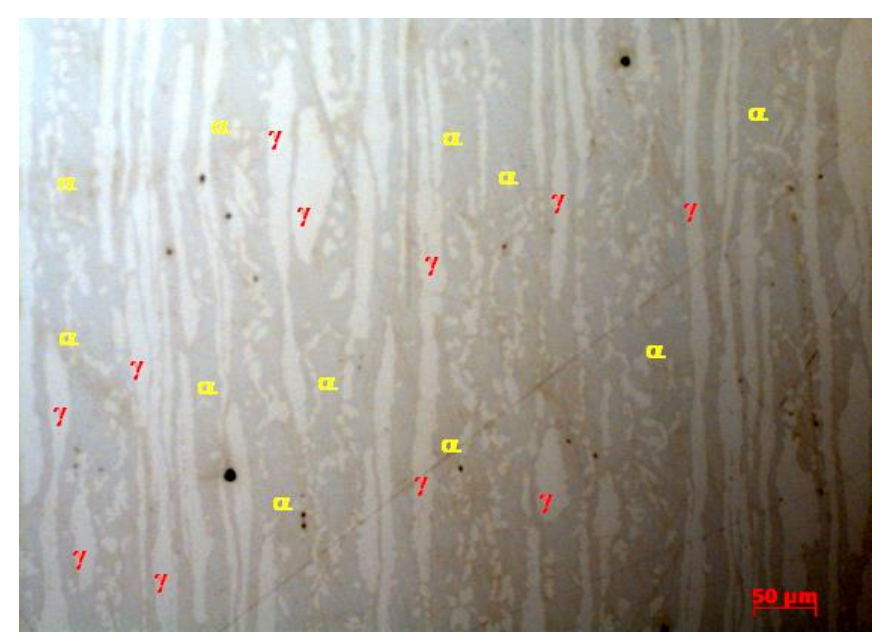

Figure 2: optical microscopy image of UNS S32101 sanded, polished, duplex stainless steel with Murakami attack to reveal austenitic $(\gamma)$ and ferritic $(\alpha)$ grains, with 200x magnification.

Figure 3 shows the difference, as the ferritic grains appear darker, showing the damage caused by the entry and exit of hydrogen in the steel. In sequence, in figures 4 and 5, the optical micrographs of the duplex stainless steel of the UNS S32205 type are shown. Figure 4 is an optical microscopy image of the UNS S32205 duplex stainless steel sanded, polished, without hydrogenation, with Murakami attack to reveal the austenitic and ferritic grains. While in figure 5 is the micrograph of the UNS S32205 duplex stainless steel sanded, polished, hydrogenated for 4 hours and degassed for seven days.

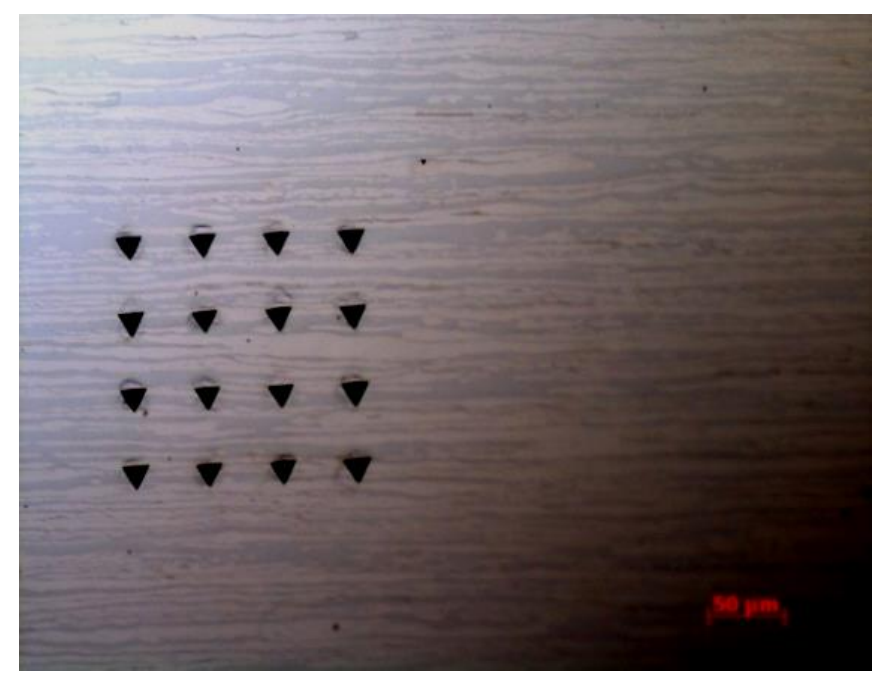

Figure 4: optical microscopy image of sanded, polished, UNS S32205 duplex stainless steel with Murakami attack to reveal austenitic $(\gamma)$ and ferritic $(\alpha)$ grains, with a 200x magnification. Source: the author. 


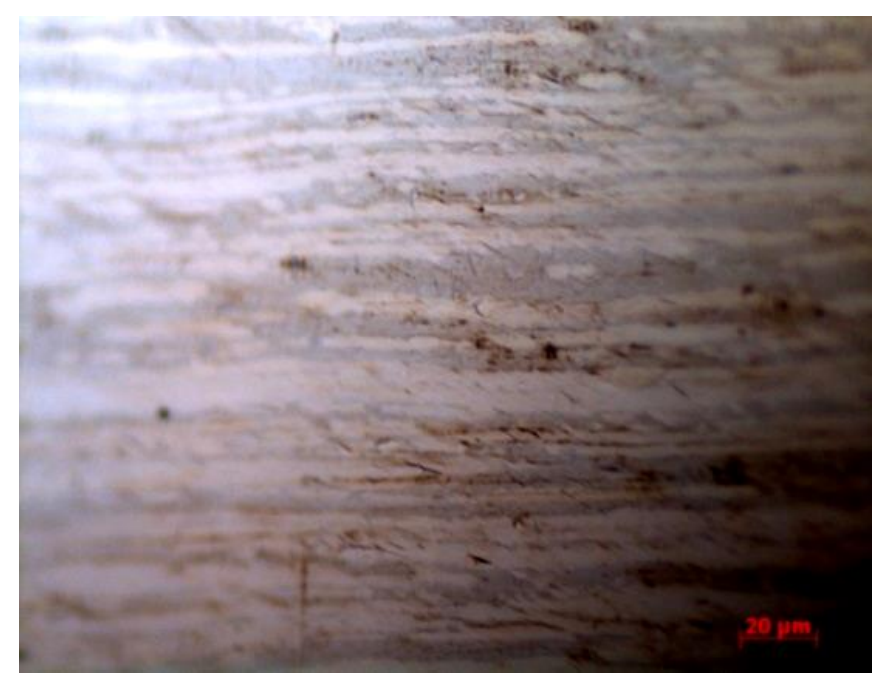

Figure 5: optical microscopy image of UNS S32205 duplex stainless steel sanded, polished, hydrogenated for $4 \mathrm{~h}$ and degassed for 7 days, with a 500x magnification. Source: the author.

It is observed, in hydrogenated samples of duplex stainless steel of type UNS S32205 (figure 5), by means of micrographs, that the ferritic grains did not darken, as occurred in hydrogenated samples of duplex stainless steel of type UNS S32101 (figure 3).

Due to the limitations of optical microscopy, scanning electron microscopy images were sought to better clarify the damage caused by the entry and exit of hydrogen from the material. Figures 6 and 7 are SEM images of duplex stainless steels of the type UNS S32101 and UNS S32205 respectively, hydrogenated for $4 \mathrm{~h}$ and degassed for a week. Thus, it can be seen that in figure 6, the microcracks in the austenitic and ferritic grains were evidenced, and in addition to these the presence of corrosion - by pites - located in the ferritic grains. Since, such corrosion is characterized by small pits that form in the material and these normally penetrate into the metal from the surface. This type of corrosion, being below the surface, is almost imperceptible, as it is often left undetected until the failure occurs. In the image of figure 7 of the UNS S32205 duplex stainless steel, several cracks are noted, both in austenitic grains and in ferritic grains. In the image of figure 7 of the UNS S32205 duplex stainless steel, several cracks are noted, both in austenitic grains and in ferritic grains. However, no localized corrosion is observed as seen in figure 6 of UNS S32101 duplex stainless steel.

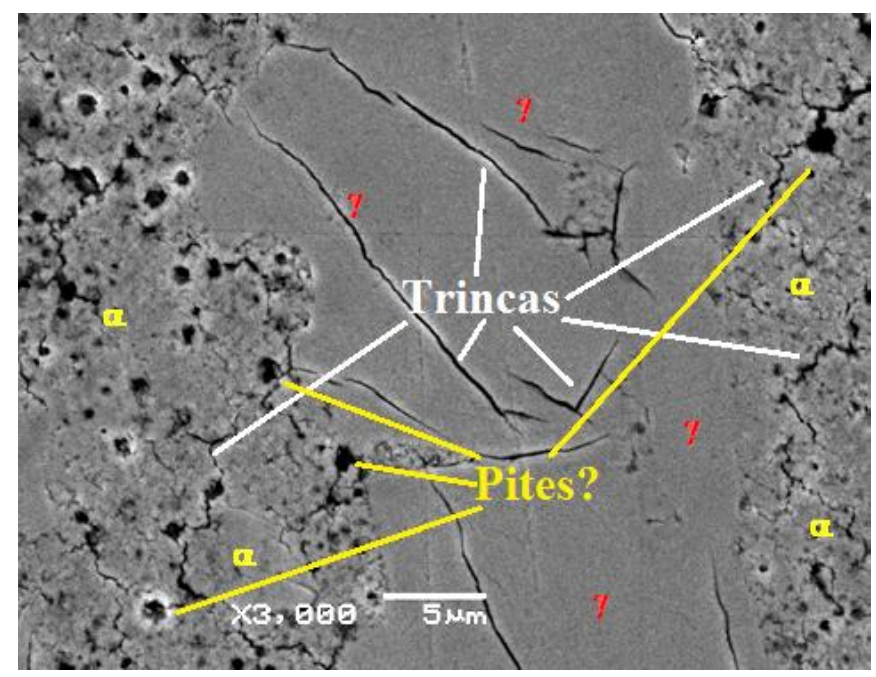

Figure 6: Scanning electron microscopy image of UNS S32101 duplex stainless steel sanded, polished, hydrogenated for $4 \mathrm{~h}$ and degassed for 7 days, with a 3000x magnification. Source: the author. 


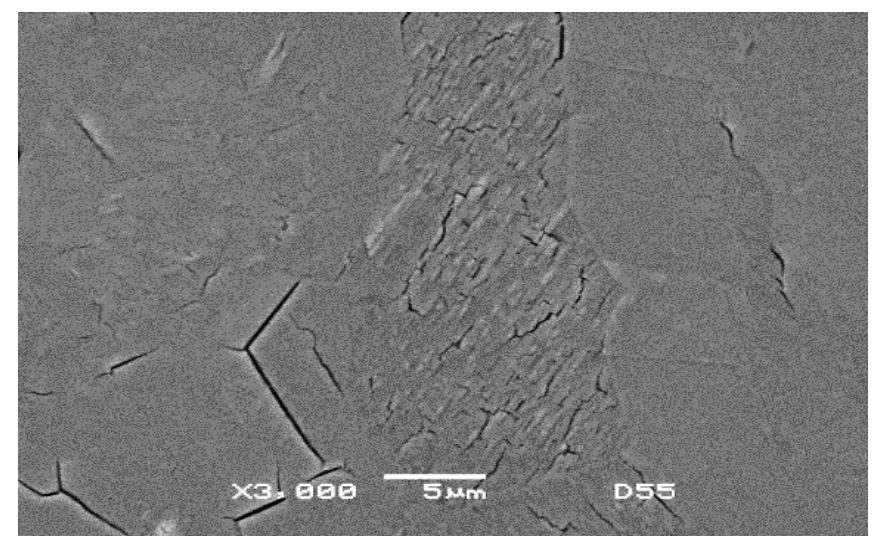

Figure 7: Scanning electron microscopy image of UNS S32205 duplex stainless steel sanded, polished, hydrogenated for $4 \mathrm{~h}$ and degassed for 7 days, with a 3000x magnification. Source: the author.

At first, it is noteworthy that the X-ray diffraction technique was used to verify which phases are present in the material before and after hydrogenation. For this purpose, a diffractometer with Bragg-Bretano geometry was used which uses a monochromator at the beam outlet, with copper tube. Thus, graph 1 shows the comparison of UNS S32101 duplex stainless steel without hydrogenation (black curve), hydrogenated for 4 hours and degassed for seven days (red curve). Graph 2 is a comparison of UNS S32205 duplex stainless steel in the same conditions, where the black curve is without hydrogenation and the red curve after hydrogenation and degassing. In these it is possible, clearly, to observe the phase transformation of such steels after the entry and exit of hydrogen.

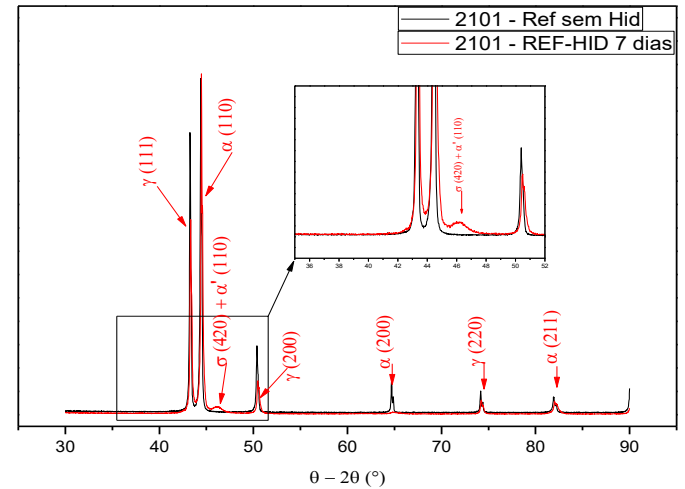

Graph 1: X-ray diffractogram of UNS S32101 duplex stainless steel without hydrogenation (black curve) and hydrogenated for 4 hours, after seven days of degassing (red curve), showing the peaks of phases $\alpha, \gamma$ and possibly $\sigma$ and $\alpha^{\prime}$ present in steel. Source: the author.

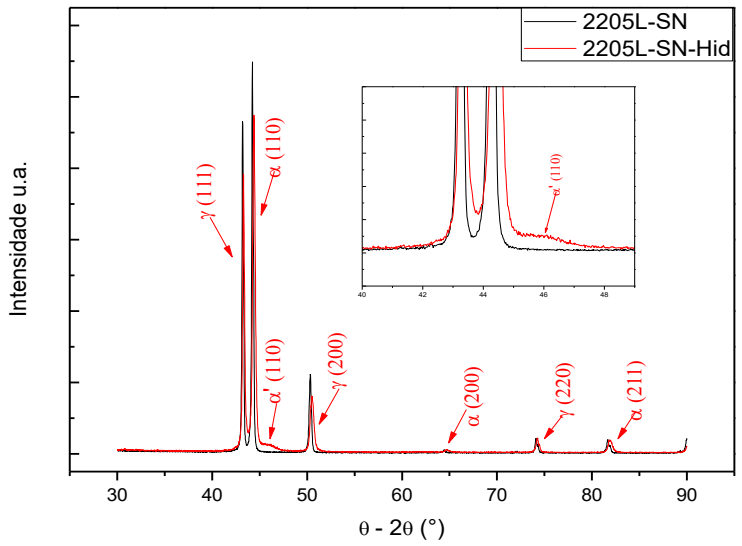

Graph 2: X-ray diffractogram of UNS S32205 duplex stainless steel without hydrogenation (black curve) and hydrogenated for 4 hours, after seven days of degassing (red curve), showing the peaks of phases $\alpha, \gamma$ and $\alpha^{\prime}$ present in the steel. Source: the author. 
It is noteworthy that in the samples of duplex stainless steels before hydrogenation, only the $\alpha$ and confirmou phases were confirmed. It is evident that the transformation of the $\gamma$ phase $\alpha$ ' phase (transformation from austenite to martensite $-\square^{\gamma} \rightarrow \varepsilon \rightarrow \alpha^{\prime}$ ) was expected, due to a percentage of approximately 50\% of austenitic phase in the UNS S32101 duplex stainless steel [11,12]. According to these authors, the $\varepsilon$ phase is a stacking failure that arises during hydrogenation. And over time the phase $\varepsilon$ would become martensite $\alpha^{\prime}$. However, according to the literature the $\alpha^{\prime}$ peak is approximately $45.95^{\circ}$ and the $\varepsilon$ peak is approximately $48^{\circ}$ and the peak shown in graph 1 of the UNS S32101 duplex stainless steel samples is approximately $46.18^{\circ}$. This peak coincides with the sigma phase peak $(\sigma)$ according to $[8,13-15]$.

It is known that hydrogen induces the formation of Cr23C6 precipitates in the ferritic grains [8], these ferritic grains are inconsistent with the austenitic grains, but are highly stressed due to the precipitates that have arisen, so that there is a sufficient high interfacial energy for the $\sigma$ phase formation. Padilha and Rios [16] guarantee that both carbon and nitrogen are insoluble in the $\sigma$-phase and, as a consequence, the $\sigma$-phase is precipitated commonly after the precipitation of carbides and /or nitrides, and the formation of this favors corrosion by pites. Therefore, explaining the localized corrosion that appears in figure 6 . It is clear that hydrogen induces the formation of precipitates of the Cr23C6 type [8].

Graph 2, referring to the UNS S32205 duplex stainless steel, shows the peaks of the $\alpha, \gamma$ phases and a peak at approximately $45.96^{\circ}$ which is transformation of the austenitic phase $\gamma$ into the martensitic structure $\alpha^{\prime}$ [17-19]. However, the peak at $46.18^{\circ}$ for phase $\sigma$ is not evident as in UNS S32101 duplex stainless steel. The fact that the peak of phase $\sigma$ is not detected explains the absence of pitting-type localized corrosion. Since, the decrease in corrosion resistance is related to the formation of phase $\sigma$ [20]. This corrosion resistance is related to the fact that in UNS S32205 duplex stainless steel contains 3\% molybdenum on average and in UNS S32101 duplex stainless steel the molybdenum content is $0.5 \%$, that is, UNS steel S32205 contains six times more molybdenum than UNS S32101 steel [21].

\section{Conclusions}

Finally, it was possible to state, after the study, that hydrogen can induce the formation of the sigma phase $(\sigma)$ at room temperature in UNS S32101 duplex stainless steel. And as initially predicted, this duplex stainless steel was more susceptible to the deleterious effects of hydrogen, when compared to UNS S32205 duplex stainless steel under similar conditions.

Likewise, it was determined that in UNS S32101 duplex stainless steel, after hydrogenation, there was an intense surface cracking, as well as pitting corrosion. This is due to the formation of the sigma phase $(\sigma)$, a phase that favors pitting corrosion. In the duplex stainless steel of the UNS S32205 type, numerous cracks also arose due to the embrittlement by hydrogen and in addition there was a transformation from the austenitic $(\gamma)$ to martensitic $\left(\alpha^{\prime}\right)$ phase, as predicted. However, it did not form a sigma phase $(\sigma)$ and did not show pitting corrosion, this is probably due to the fact that this steel contains a higher molybdenum content than UNS S32101 duplex stainless steel.

\section{References}

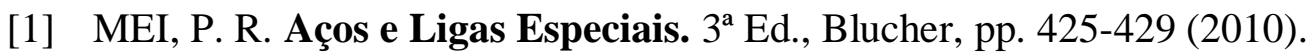

[2] VERMA J., TAIWADE R. V., KHATIRKAR R. K., KUMAR A. A Comparative Study on the Effect of Electrode on Microstructure and Mechanical Properties of Dissimilar Welds of 2205 Austeno-Ferritic and 316L Austenitic Stainless Steel. Materials Transactions, vol. 57, pp 494 500, (2016).

[3] MANOVA, D., MÄNDL, S. Nitrogen Transport in Expanded Austenite Formed in Stainless Steels and $\mathrm{CoCr}$ Base Alloys. Materials Performance and Characterization, vol. 6, No. 4, pp 617-641, ,(2017).

[4] COLPAERT, H. Metalografia dos produtos siderúrgicos comuns, Edgard Blucher, 4a ed., São Paulo, (2008). 
[5] CARTER, T. S.; CORNISH, L. A. Hydrogen in Metals. Engineering Failure Analysis, vol. 8, p. 113-121, (2001).

[6] YANG J., ZHENG W., HE Y., GAO Z. Hydrogen diffusion mechanism of the single-pass welded joint in welding considering the phase transformation effects. Journal of Manufacturing Processes, vol. 36, pp 126-137, (2018).

[7] WANG Y., WU X., WU W. Effect of $\alpha$ ' Martensite Content Induced by Tensile Plastic Prestrain on Hydrogen Transport and Hydrogen Embrittlement of 304L Austenitic Stainless Steel. Metals, vol. 8, pp 660, (2018).

[8] Oliveira A. M. C., PAREDES R. S. C., GODOI W. C., VAZ A. P. Duplex Stainless Steel of Type UNS S32101 and Ferritic Stainless Steel of Type AISI 430 Subjected To Cathodic Hydrogenation. International Journal of Scientific Research and Management, vol. 8, pages 1728, (2020).

[9] HARDIE D.,CHARLES_E.A., LOPEZ_A.H. Hydrogen embrittlement of high strength pipeline steels. Corrosion Science, vol. 48, Issue 12, pages 4378-4385, (2006).

[10] LOTO R. T. Corrosion resistance and morphological deterioration of 316Ti austenitic, GX4CrNiMo16-5-1 martensitic and 444 ferritic stainless steels in aqueous corrosive environments. Results in Physics 14, (2019).

[11] KOYAMA M., AKIYAMA E., LEE Y. K., RAABE D., TSUZAKI K., Overview of hydrogen embrittlement in high-Mn steels, Int. J. Hydrog. Energy 42 (17) (2017) 12706-12723.

[12] ZINBI , A. , BOUCHOU, A., Delayed cracking in 301 austenitic steel after bending process: Martensitic transformation and hydrogen embrittlement analysis, Engineering Failure Analysis (2009).

[13] MICHLER, T.; NAUMANN, J., Hydrogen environment embrittlement of austenitic stainless steels at low temperatures, International Journal of Hydrogen Energy 33, p. 2111 - 2122 ( 2008 ).

[14] GAVRILJUK V.G., MOGILNY G.S., TEUS S.M., SHYVANYUK V.N. Plastic deformation and phase transformations in austenitic steels in the course of hydrogen charging and subsequent mechanical tests. Materials Science and Engineering A, vol. 648, pp 260-264, (2015).

[15] MACADRE A., TSUCHIYAMA T., TAKAKI S. Hydrogen-induced increase in phase stability in metastable austenite of various grain sizes under strain. J Mater Sci 52, pp 3419-3428, (2017).

[16] CHEN, T.H.; YANG, J.R. Effects of solution treatment and continuous cooling on $\sigma$-phase precipitation in a 2205 duplex stainless steel. Materials Science and Engineering A 311, p. 28-41, (2001).

[17] MEI P.R., GUIMARÂES A. A. Precipitation of carbides and sigma phase in AISI type 446 stainless steel under working conditions. Journal of Materials Processing Technology, pp 155-156 (2004).

[18] GAO J., JIANG Y., DENG B., ZHANG W., ZHONG C., LI J. Investigation of selective corrosion resistance of aged lesn duplex stainless steel 2101 by non-destructive electrochemical techniques. Electrochimica Acta 54, pp 5830-5835 (2009).

[19] PADILHA, A.F.; RIOS, P.R. Decomposition of Austenite in Austenite Stainless Steels. ISIJ Internacional, 42, pp 325-337(2002).

[20] [17] ALYOUSIF, O. M.; NISHIMURA, R. A hydrogen embrittlement mechanism for sensitized types 304, 316 and 310 austenitic stainless steels in boiling saturated magnesium chloride solutions. Corrosion Science 52, p. 7-13 (2010).

[21] MICHLER, T.; LEE, Y.; GANGLOFF, R. P.; NAUMANN, J. Influence of macro segregation on hydrogen environment embrittlement of SUS316L stainless steel. International Journal of Hydrogen Energy 34, pp 3201 - 3209 (2009).

[22] MINE, Y.; HORITA, Z.; MURAKAMI, Y. Effect of hydrogen on martensite formation in austenitic stainless steels in high-pressure torsion. Acta Materialia 57, pp 2993-3002 (2009). 
[23] ZHANG B., MA X.L. A review Pitting corrosion initiation investigated by TEM. Journal of Materials Science \& Technology, vol. 35, pp 1455-1465, (2019).

[24] Ezuber H. M., El-Houd A., El-Shawesh F. Effects of sigma phase precipitation on seawater pitting of duplex stainless steel. Science Direct - Desalination, Vol. 207, pages 268-275, (2007).

Doctor Angela Maria Cordeiro de Oliveira

Rua: Geraldino Ramiro dos Santos, 762

Graduate Program in Engineering and Science of Materials - PIPE

Federal University of Paraná

Coronel Avenue Francisco Heráclito dos Santos, 100.

Curitiba, CEP: 81.531-980

Brazil 